\title{
Sero-Prevalence and Risk Factors of Hepatitis C Virus Infection Among Children Diagnosed With Cancer in Lagos Nigeria.
}

Chukwudi Okoli ( $\boldsymbol{\sim}$ drchuksokoli@yahoo.com )

Lifeline Children's Hospital https://orcid.org/0000-0002-0470-7164

\section{Abideen Salako}

Nigeria Institute of Medical Research Yaba Lagos

Ifeyinwa Nwafia

College of Medicine University of Nigeria Enugu Campus

\section{Research}

Keywords: Sero-Prevalence, risk factors, Hepatitis C virus, children, cancers, Nigeria

Posted Date: July 23rd, 2020

DOI: https://doi.org/10.21203/rs.3.rs-38375/v1

License: (c) (i) This work is licensed under a Creative Commons Attribution 4.0 International License.

Read Full License 


\section{Abstract}

Introduction: $\mathrm{HCV}$ is a blood borne viral infection transmitted mainly via blood and blood product transfusion. Children diagnosed with cancers are especially in the high-risk group for infection with blood transmissible infections like HCV because of their dependence on blood and blood product. Children with cancer are also exposed to unwholesome practice like scarification marks. Also children with cancer because of their immunocompromised state lack the ability effectively clear HCV after an acute infection, there are therefore very likely to have chronic infections.Because of the above reason it became necessary to determine the prevalence and risk factors for HCV infection among children with cancer at Lagos .

Methods: We designed a descriptive cross-sectional study conducted over a 12 months period at the Oncology ward and outpatient clinics of LUTH.

Result: 50 children with cancers were recruited age range 7 months and 17 years. Ninety percent of them has been exposed to blood transfusion while $32 \%$ and $18 \%$ of them has had surgery and scarification marks respectively. The most diagnosed cancer was ALL with $44 \%$. And $82 \%$ of the subjects were on chemotherapy at the time of recruitment. The sero-prevalence of HCV infection among those with cancer was $0 \%$.

Conclusion: The sero-prevalence of HCV infection was zero percent despite significant exposure to blood transfusion and other risk factors.

\section{Introduction}

Hepatitis $\mathrm{C}$ virus (HCV) infection is a blood borne viral infectious disease transmitted mainly via the parenteral route [1, 2]. It is caused by an enveloped single stranded positive sense ribonucleic acid (RNA) virus [3], a member of the flaviviridea family.

The prevalence of HCV infection varies from one location to another. It is estimated that about 130 million (2\% prevalence) people globally are HCV-positive [4.] The study done in the South West among Nigerian children documented a prevalence of $0 \%,[5]$ while a similar study in Benin reported a prevalence of $0.25 \%$ [6].

Of those infected or exposed to the virus, $40 \%$ recover fully and the remainder become chronic carriers. Twenty per cent $(20 \%)$ of the chronic carriers will develop cirrhosis while about $20 \%$ of patients with cirrhosis will develop liver cancer $[7,8]$ leading to significant morbidity and mortality. A robust immune system helps to clear HCV after initial infection. In children with cancer especially haematologic cancers, the immune system is weakened and HCV infection is likely to progress to chronic HCV infection.

Till date, only few studies have documented the sero-prevalence and risk factors of HCV infection among children with various cancers including liver cancer especially in our environment. Studies showed that 
blood level of hepatitis C viral RNA increases during immunosuppression and application of chemotherapy, both of which are hallmarks of cancer [9]. Two independent researchers reported an HCV sero-prevalence of $0.7 \%$ and $0.9 \%$ respectively among children living with cancer in Turkey [10, 11], both studies did not find any risk factor to be significant in the acquisition of the virus. Sharaf-Eldeen on the other hand in Egypt reported an HCV prevalence of $43 \%$ with blood product transfusion and parenteral injections as the major risk factors for the acquisition of HCV in a study involving 100 children with cancer [12]. In another study in Egypt in 2007, 1042 children aged 1-9 years were screen for HCV infection. The authors reported that of those with HCV positive antibody, $52.9 \%$ had injection by nonmedical personal, $16.7 \%$ blood transfusion, $11.1 \%$ were exposed to used syringe while $78.6 \%$ of them had ear piercing thus highlighting the roles this risk factors play in the acquisition of the virus[13].

$\mathrm{HCV}$ infection predisposes to primary liver cell carcinoma in its chronic stage, though this has not been reported widely in the paediatric population and it could also lead to chronic infection and worsen the outcome of children treated for other types of childhood cancers more commonly haematological cancers, this is because of a progression to liver cirrhosis in about $20 \%$ of cases, and increased incidence of chronic hepatitis[14].

In Nigeria, there is a knowledge gap on the prevalence and risk factors of HCV infection among children with cancer despite their heavy dependence on blood and blood products transfusions and its attendant risk. The most common route of HCV transmission is by blood and blood products transfusion. Children with cancer receive blood and blood products frequently, highlighting their heightened risk of acquired blood-transmissible infections including $\operatorname{HCV}[12]$. Studies $[11,12,15]$ done elsewhere have implicated blood and blood product transfusions, as a significant risk factor amidst other factors in the acquisition of HCV especially among children with cancer. In Nigeria, researchers in Lagos[16], South East[17] and North Central[18] in their various studies among blood donors reported a relatively higher sero-prevalence in this group, whom children with cancers depend on to meet their blood and blood product needs.

Because HCV infection varies from region to region and because of the central role the liver plays in the metabolism of several medications including anti-cancer medications, it is important to determine how common HCV infection is among children diagnosed with cancer attending the Lagos Nigeria.

The aim therefore of the study was to determine the sero- prevalence and risk factors of HCV infection among children diagnosed with cancer in Lagos Nigeria.

\section{Methodology}

\section{Study design and location}

The study was a descriptive cross-sectional study conducted over a 9 month period at the paediatrics haematology/oncology ward of the Lagos University Teaching Hospital (LUTH) Idi-araba Lagos.

\section{Study population}


Subjects were children with histologically confirmed diagnosis of cancer on admission at the Oncology ward and those on routine follow-up for chemotherapy drugs.

\section{Data collection}

Information obtained was on history of blood/blood product transfusion, units of blood/blood products transfused, parenteral injections, scarification marks, previous surgery, whether or not they had bone marrow aspirate and treatment for HCV infection in the preceding 3 months prior to commencement of the study.

\section{Laboratory analysis}

The plasma was used for analysis. Samples were centrifuged at $2000 \mathrm{rpm}$ and $1 \mathrm{ml}$ of plasma collected for analysis.

HCV antibody was determined using a fourth (4th ) generation, HCV Ab Version 4.0 Enzyme Immunoassay for the determination of anti-Hepatitis $C$ Virus antibody in human serum and plasma by DIA.PRO Diagnostic Bioprobes Srl Italy. This kit has a better sensitivity $(100 \%)$ and specificity $(100 \%)$ compared to the earlier generation which were used for existing studies.

\section{Ethical Consideration}

Approval was sought and obtained from the Lagos University Teaching Hospital Health Research and Ethics Committee prior to commencement of the study. Informed consent was also obtained from the parents and care givers. Assent was obtained from children who were above 10 years of age.

\section{Data analysis}

Analysis was done using statistical package for social science (SPSS), version 17. Categorical variable were compared using the Chi square or Fisher's exact test, while continuous variables were analysed using the student's $t$ test. Statistical significance was taken at $p<0.05$.

\section{Results}

A total of 50 children diagnosed with cancer were recruited between September 2015 and May 2016 for the study. Table 1

\section{Types of cancers seen in the subjects}

The most diagnosed cancer in this study was Acute Lymphoblastic Leukamia (ALL) which was seen in $22(44 \%)$ of the subjects. Figure 1 


\section{Chemotherapy use and duration in the study population}

Eighty two per cent of the study population were on chemotherapy with 33 of this number having received it for less than one year.

\section{Prevalence of HCV Infection}

Table 2 show the prevalence ( $0 \%$ ) of HCV infection amongst the subjects.

Table 2.

\section{Risk factors for HCV acquisition among the study population}

Regarding the transfusion of blood and blood products, table 3 showed that $45(90 \%)$ of subjects with cancer had blood transfusion.

Concerning platelet transfusion, $50 \%$ of the children with cancer had received platelet transfusion. Similarly $32 \%$ of the subjects have had a form of surgery.

Table 3 , also showed that $18 \%$ of the subjects were exposed to scarification marks and also practice sharing razor blade and toothbrush.

Despite the increased exposure to both blood and blood product transfusion and other risk factors to the acquisition of the HCV amongst the subject none of them tested positive to the HCV antibodies.

Table 3

\section{Discussion}

In the current study the sero-prevalence of HCV infection in patients with cancer was $0 \%$. This result is similar to the findings of an earlier study [5] in south west Nigeria and another in Benin [6] where they reported a sero-prevalence of $0 \%$ and $0.25 \%$ respectively amongst general population of Nigeria children.

The sero-prevalence of $\mathrm{HCV}$ infection in the general population vary from one region or country to another, this variability is more in children with cancer due to their exposures to predisposing risk factors.

The low sero-prevalence of HCV infection in our study could be the combined effect of factors which includes the low sero-prevalence of HCV infection in the general population of Nigeria children and the asymptomatic nature of HCV infection in children as demonstrated by other workers in South West Nigeria and Benin respectively[22]. The low sero-prevalence could also be due to the robust and extensive National blood transfusion programme in place since year 2000, which has reinforced the mandatory 
screening for HCV and other transfusion transmittable infections, therefore resulting in safer blood and blood product in our various blood banks[23]. This effort at the national level have been augmented by the intensive blood transfusion programme put in place by LUTH at its blood bank, where most of our study subjects source their blood and blood products.

The results of the present study are also similar to the finding by different researchers in Turkey $[10,11]$ who reported an HCV antibody sero- prevalence of $0.7 \%$ and $0.9 \%$ respectively among children diagnosed with cancer in Turkey. Turkey has a sero-prevalence of $1.2 \%-4 \%$ in the general population.

However the results from this study differs from that reported in a study on Hepatitis B and C virus in Egyptian children with Malignancy[12] where they studied 100 children with cancer and documented a HCV antibody prevalence of $43 \%$ also using a 3rd generation ELISA kit. This high prevalence might be explained by the high HCV sero-prevalence of $3 \%-9 \%$ in the general population of Egyptian children [19]. Another study with a high HCV infection sero-prevalence was that reported by worker [20] in Italy in 1994, among children managed for ALL, where they documented a prevalence of $43 \%$. The high sero-prevalence compared to our series can be explained by the long duration of their study and the fact that the study covered the period prior to the institutionalisation of mandatory HCV screening for donor blood. Similarly a study on Seroprevalence of hepatitis B, hepatitis C, and human immunodeficiency virus infections in children with cancer at diagnosis and following therapy in Turkey[15], in 2000 reported a sero-prevalence of $14 \%$, this high prevalence was attributed to lack of proper screening of blood for HCV during the study period, unlike in the present study which was done in a locality where screening for HCV is mandatory and comprehensive.

The type of cancers diagnosed in the subjects did not significantly influence the sero-prevalence of HCV infection in the study. The finding is similar to what was obtained by different workers in Italy [21], Egypt [12] and Turkey [11], these studies did not find any significant relationship when these variables were compared.

Regarding the history of blood transfusion and the sero-prevalence of HCV infection, blood transfusion was not a significant risk factor amongst the subjects, this might be the result of the universal mandatory screening of blood donors for HCV at various blood banks in the study locality. This finding differs from the result obtained by researchers in Egypt[12] in 2007 , Italy in 1994[20], and Turkey[15, 14] who found a significant relationship between history of blood transfusion and HCV sero-prevalence in their studies.

In the present study, the researchers was not able to asses for any significant relationship between the sero-prevalence of HCV infection and exposure to surgical procedures as no case of HCV was observed. This finding is like that obtained in Egypt [12] and Turkey [11] in their study. However some researchers in Egypt in their study involving children with cancer in Egypt found that certain invasive procedures other than the most commonly documented types are significant in the acquisition of HCV.

Finally, the study could not asses for any association between scarification marks, parenteral injections and sharing of razor blades and tooth brush and the sero-prevalence of HCV infection in our study. 
However authors [11] in Turkey in a similar study in cancer patient reported similar findings in their study despite having a higher HCV infection sero-prevalence. This however differs from what researcher [23] found in Sokoto, Nigeria when they screened 300 children with sickle cell anaemia for HCV and found significant relationship between parenteral injections and sero-prevalence of HCV infection.

\section{Conclusion}

This study recorded zero ( $0 \%$ ) prevalence for $\mathrm{HCV}$, despite the exposures to various risk factors for HCV acquisition among the children with cancers recruited for this study.

\section{Limitations}

A limitation of this study is the low sample size which might account for the zero prevalence of HCV in the study population, the sample size is also a reflection of the confirmed cases of cancers at the study centre. The sero-prevalence of the study population could also be a reflection of the low sero-prevalence of HCV in the general population of Nigerian children.

\section{Declarations}

\section{Conflict of Interest}

The authors do not have any conflict of interest to declare.

\section{Authors Contribution}

All the authors contributed equally from conception to manuscript preparation.

\section{Acknowledgment.}

The authors would want to profoundly thank the children living with cancers and there parent for their support throughout this study.

\section{Funding.}

The authors do not receive any funding or grant for this research or in the preparation of the manuscript

\section{Author's details}

${ }^{1}$ Lifeline Children's Hospital 133 Ogulana Drive Surulere, Lagos Nigeria

${ }^{2}$ Nigeria Institute Medical Research Yaba, Lagos Nigeria

${ }^{3}$ College of Medicine University of Nigeria Enugu Campus.

\section{References}


1. Ryan KJ, Ray CG. Hepatitis C, Virus. Sherris Medical Microbiology 4th ed 2004:pp 551-2.

2. Amon JJ, Garfein RS, LAhdieh-Grant. Prevalence of Hepatitis $C$ virus infection among injection drug users in the United States 1994-2004. Clin Infect Dis. 2008;46:1852-8.

3. Purcell RH. Hepatitis C virus. In: Webster RG, Granoff A, editors. Encyclopedia of Virology. London: Academic Press Ltd; 1994. pp. 569-74.

4. Hutin Y, Kitler ME, Dore G, Perz J, Armstrong G, Dusheiko G, et al. "Global burden of disease (GBD) for hepatitis C". J Clin Pharmacol. 2004;44:20-9.

5. Oni AO, Harrison TJ. Genotypes of hepatitis C virus in Nigeria. J Med Virol 1996;49:178 - 86.

6. Ogboghodo B, Aigbirior M, Bazuaye G, Ebomoyi M, lyave V. Human immunodeficiency virus-1 coinfection in children in Benin City. African Journal of Biomedical Research. 2009;12:1-6.

7. EASL International Consensus Conference on Hepatitis C. Consensus Statement. Journal of Hepatology. 1999;31:3-8.

8. Viral Hepatitis Prevention Board. Hepatitis A, B \& C: defining workers at risk1995.

9. Hwang YY, Liang RHS. Hepatitis C in Haematological Patients. Hepatitis Research Treatment. 2010;2010:961359.

10. Berberoglu $S$. The seroprevalence of hepatitis $B$, hepatitis $C$ and human immunodeficiency virus infections in paediatric oncology patients in Turkey. Postgrad Med J. 1996;72:609-11.

11. Sukran K, Ali O, Ayhan G, Gulfem E. Seroprevalence of Hepatitis B and C among Oncology Patients in Turkey. J Heath Popul Nutr 2011 Dec:652 - 65.

12. Sharaf-Eldeen S, Salama K, Eldermerdesh S, Hassan S, Semesem M. Hepatitis B and C virus in Egyptian children with Malignancy. J Med Sci 2007:1003-8.

13. El-Raziky MS, El-Hawary M, Esmat G, Abouziad AM, El-Koofy N, Mohsen N, et al. Prevalence and risk factors of asymptomatic hepatitis $\mathrm{C}$ virus infection in Egyptian Children. World J Gastroenterol. 2007;13:1828-32.

14. Sevinir B, Meral A, Günay Ü, Özkan T, Özuysal S, Sinirtas M. Increased risk of chronic hepatitis in children with cancer. Med Pediatr Oncol. 2003;40:104-10.

15. Kebudi R, Ayan I, Yílmaz G, Akící F, Görgün O, Badur S. Seroprevalence of hepatitis B, hepatitis C, and human immunodeficiency virus infections in children with cancer at diagnosis and following therapy in Turkey. Med Pediatr Oncol. 2000;34:102-5.

16. Adejare EA, Oyegbami TO, Azenab OA, Abioye AO, Ahmed IB, Awokola OT. et a. Seropositivity of Hepatitis B and C among Blood Donors in Private Laboratories in Lagos Nigeria. Journal of Biology Agriculture Healthcare. 2015;5:2224-3208.

17. Chukwura EF, Ogbodo SO, Obi GO. Seroprevalence of Hepatitis $C$ virus infection among blood donors in South Eastern State of Nigeria. Biomed Res. 2015;16:133-5.

18. Nwannadi IA, Alao O, Shoaga L. Hepatitis $C$ among Blood Donors In A Teaching Hospital In North Central Nigeria. IOSR Journal of Dental Medical Science (IORS-JDMS). 2014;13:20-3. 
19. Mostafa Habib M, Mohamed K, Abdel-Aziz F, Magder LS, Abdel-Hamid M, Gamil F, et al. Hepatitis C virus Infection in a community in the Nile Delta: Risk factors for Seropositivity. Hepatology. 2001;33:248-53.

20. Arico M, Maggiore G, Silini E, Bono F, Vigano C, Cerino A, et al. Hepatitis C virus infection in children treated for acute lymphoblastic leukamia. Blood. 1994;84:2911-22.

21. Cesaro S, Petris MG, Rossetti F, Cusinato R, Pipan C, Guido M, et al. Chronic hepatitis C virus infection after treatment for pediatric malignancy. Blood. 1997;90:1315-20.

22. Kocabaş E, Aksaray N, Alhan E, Tanyeli A, Köksal F, Yarkin F. Hepatitis B and C virus infections in Turkish children with cancer. Eur J Epidemiol. 1997;13:869-73.

23. Jibrin B, Jiya N, Ahmed H. Seroprevalence of hepatitis $\mathrm{C}$ virus antibody and its associated risk factors in children with sickle cell anaemia. Sub-Saharan Afr J Med. 2014;1:20-5.

\section{Tables}

Table 1: Socio-demographic characteristics of study population

\begin{tabular}{llll}
\hline Variables & $\begin{array}{c}\text { Subjects } \\
\mathrm{n}=\mathbf{5 0}(\%)\end{array}$ & $\mathrm{q}^{2}$ & $\mathrm{p}$ Value \\
\hline Age & & & \\
$<5$ years & $24(48.0)$ & & \\
510 years & $16(32.0)$ & 0.2 & 0.903 \\
10 years & $10(20.0)$ & &
\end{tabular}

Sex

Female

18 (36.0)

Male

$32(64.0)$

2.61

$0.075^{*}$

SE Status

Class II

$33(66.0)$

Class III

$12(24.0)$

Class IV

$5(10.0)$

$0.9 \quad 0.641$

Table 2: Prevalence of HCV infection in the total population studied 


\begin{tabular}{clcc}
\hline Variables & $\begin{array}{l}\text { Subjects } \\
\mathrm{n}=\mathbf{5 0}(\%)\end{array}$ & $\square^{2}$ & $\mathrm{p}$ value \\
\hline HCV results & & & \\
Negative & $50(100.0)$ & & \\
Positive & $0(0.0)$ & 1.0 & $0.500^{*}$ \\
\hline
\end{tabular}

The $p$ value $<0.05$ and * represent Fisher`s exact $p$-value.

Table 3: Risk factors for HCV acquisition in the study population 


\begin{tabular}{llll}
\hline Variables & Subject & $\square^{2}$ & p value \\
$n=50(\%)$ & & \\
& & \\
\hline
\end{tabular}

Blood transfusion
No
$5(10.0)$
Yes

$45(90.0) \quad 22.2 \quad 0.000^{*}$

Duration

Since first

Transfusion **
$<1$ year
$32(71.1)$
1 - 2 years
6 (13.3)
$>2$ years
7 (15.6)
13.1
0.001

Unit of Blood ${ }^{\star *}$
1 - 2 unit (s)
21 (46.7)
3 - 5units
$11(24.4)$
$>5$ units
$13(28.9)$
4.6
0.100

Platelet transfusion

$\begin{array}{llll}\text { No } & 25(50.0) & & \\ \text { Yes } & 25(50.0) & 33.3 & 0.000^{*}\end{array}$

Surgery

$\begin{array}{llll}\text { No } & 34(68.0) & & \\ \text { Yes } & 16(32.0) & 19.1 & 0.000^{*}\end{array}$

Scarification marks
No
41(82.0)
Yes
9 (18.0)
$\begin{array}{ll}7.1 & 0.008^{*}\end{array}$

Share razor blades
No
41(82.0)
Yes
$9(18.0)$
2.2
$0117^{\star}$

Share toothbrush

No 
$44(88.0)$

$\begin{array}{llll}\text { Yes } & 6(12.0) & 1.1 & 0.244^{*}\end{array}$

Parenteral Injection

Yes $\quad 50(100.0)$

No $\quad 0(0.0)$

The $p$ value is taken as $<0.05$ and $* *$ the derivatives used was $n=45$ for cancers while * represent the Fisher`s exact p-value.

\section{Figures}

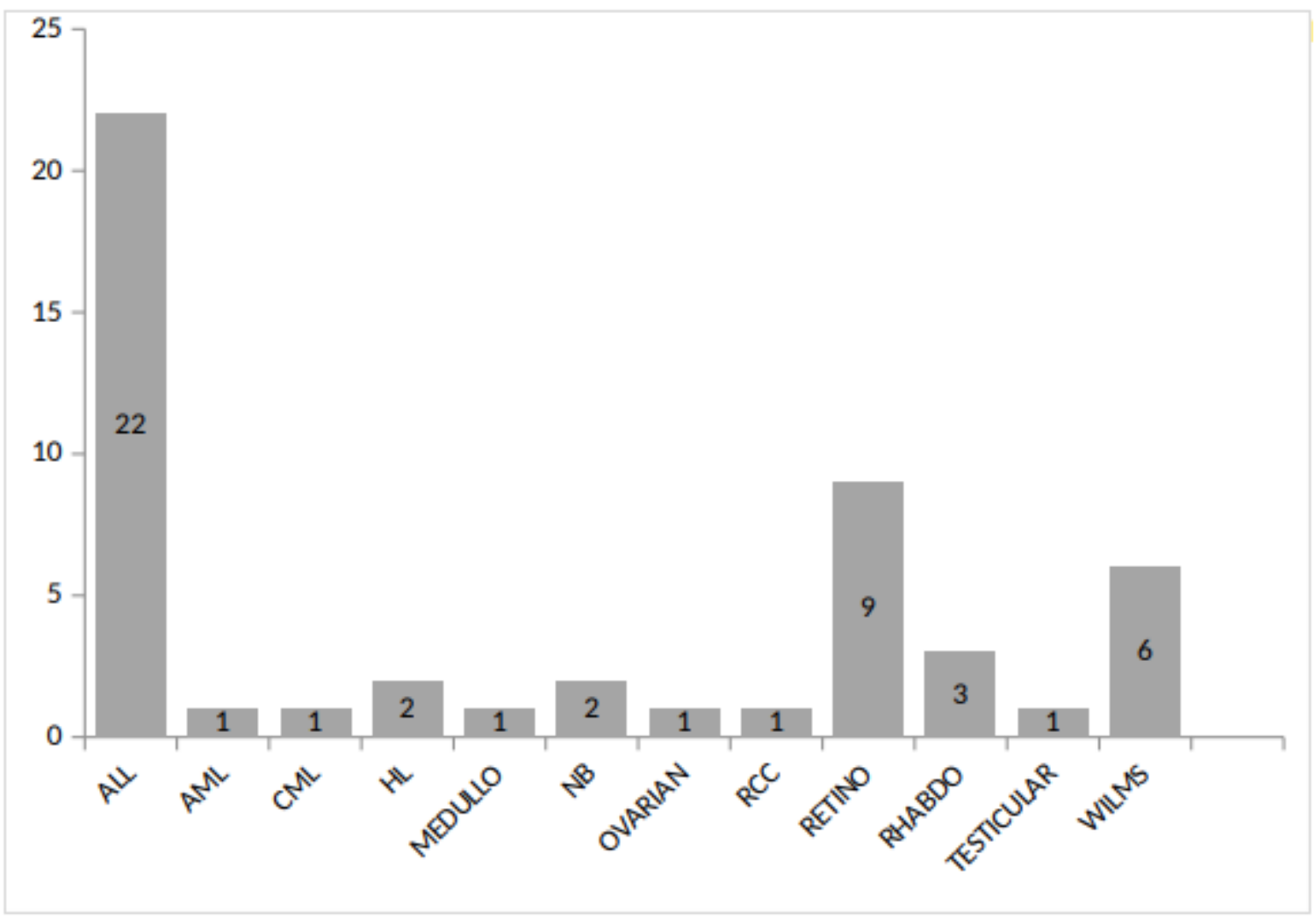

Figure 1

Distribution of types of cancer in the study population ALL-Acute Lymphoblastic Leukemia; AML-Acute myeloid leukemia; CML-Chronic Myeloid leukemia; HL-Hodgkin lymphoma; MEDULLO-Medulloblastoma; NB-Nueroblastoma; OVARIAN-Ovarian-teratoma; RCC-Renal cell carcinoma; RETINO-Retinoblastoma; RHABDO-Rhabdomyosarcoma; TESTICULAR-Testicular cancer; WILMS-Wilms tumour 